\title{
All on 4 technique assisted with computer guided surgery - A case report with 18 months follow up
}

\author{
Meenu Taneja Bhasin ${ }^{1}$, Prashant Bhasin ${ }^{2}$, Natasha Gambhir ${ }^{3}$, Akhilesh Shewale 4.** $^{*}$ \\ ${ }^{1,3}$ Reader, ${ }^{2}$ Associate Professor, ${ }^{4}$ Assistant Professor, ${ }^{1,4}$ Dept. of Periodontology, ${ }^{2}$ Dept. of Endodontics, ${ }^{3}$ Dept. of Pedodontics, \\ ${ }^{1,3}$ Santosh Dental College, Ghaziabad, Uttar Pradesh, ${ }^{2}$ Shree Bankey Bihari Dental College, Ghaziabad, Uttar Pradesh, ${ }^{4}$ Swargiya \\ Dadasaheb Kalmegh Smruti Dental College \& Hospital, Nagpur, Maharashtra, India
}

*Corresponding Author:

Email: shewaleakhilesh@gmail.com

\begin{abstract}
The All-on-4 ${ }^{\mathrm{TM}}$ technique for dental implant placement has recently generated increased interest among many patients as a highly functional, aesthetic, cost-effective treatment alternative. The technique is a good option for patients who desire fixed, naturallooking dentition, yet are not willing to undergo sinus grafting or extensive bone augmentation. Computer-guided dental implantation is a revolutionary system in dentistry. The technology offers greater accuracy and precision than do free-hand techniques, and is therefore safer. The All-on-4 method combined with guided surgery does not demand high levels of surgical expertise. Furthermore, the procedure is less traumatic for the patient - the implant is placed on the best available bone - and the technique is associated with fewer post-operative complications. We present the case of a fully edentulous patient whose maxillary and mandibular dentition was restored using a fixed prosthesis and a guided, All-on-4 technique; the patient was followed up for 18 months after surgery.
\end{abstract}

Keywords: All-on-4, Computer guided surgery, Dental implants.

\section{Introduction}

Implant dentistry is a boon for the restoration of missing teeth overcoming the many disadvantages of other conventional methods of restoration like removable and fixed prostheses.

Implant dentistry is now considered a prostheticdriven treatment, and cone beam computed tomography (CBCT) plays an important role in its planning. Using a proprietary implant software, implants can now be virtually placed at a planned position also depths and surgical guides can be prepared, leading to an accurate and predictable restoration. ${ }^{1-2}$ The All-on-4TM concept, which uses two axial implants in the anterior region and two tilted posterior implants, has been described in detail by Malo et al, with cumulative survival rates of $92.2 \%$. $^{3}$

The benefits of guided implant surgery combined with the All-on-4 technique are : (1) Simplified the procedure for technician,(2) Prosthetic-driven planning and placement, (3) Ensures the exact placement of the implant in the best available bone, (4) Improved predictability, (5)Rehabilitation of completely edentulous jaws using minimal bone volume, (6) Allows for longer implants to be placed using cortical bone anchorage - on account of the angulations of the implants,(7) Greater antero-posterior (AP) spread of the implants, helps in restoring teeth up to the first molar, (8) In patients with a composite type defect, it replaces tissue as well as teeth, and restores lost vertical dimension by $>12 \mathrm{~mm}$ in each arch. ${ }^{4-9}$

This paper presents the case of an edentulous patient whose teeth were restored using a fixed hybrid prosthesis and a computer-guided, All-on-4 technique, with the aim of evaluating crestal bone changes around each implant for 12 months after functional loading.

\section{Case Report}

A healthy, 55 year-old, completely edentulous woman reported to the clinic for replacement of her missing teeth, desiring fixed restorations only. A preliminary evaluation of her dental and medical history was obtained. Initial clinical and radiographic examination revealed severely resorbed upper and lower posterior segments, as well as bilateral maxillary sinus pneumatization [Fig. 1]. The patient was not willing to undergo only grafting or sinus lift surgical procedures.

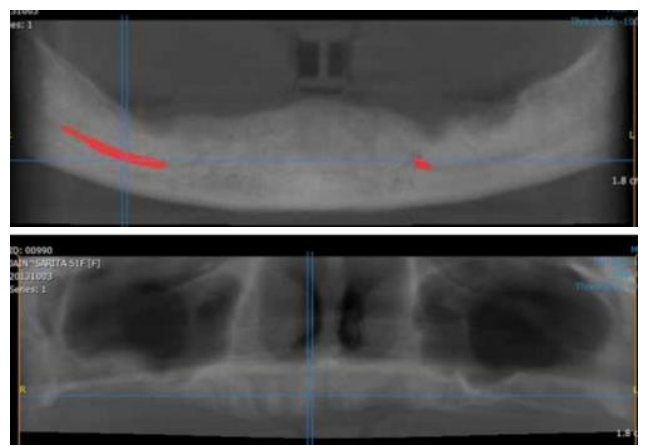

Fig. 1: Pre-operative radiograph-Maxillary \& Mandibular

After discussion of the treatment plan, the maximum cantilever length was calculated using AP spread for 4 implants - a method proposed by English in $1990 .{ }^{10}$ Upper and lower dentures were prepared for the patient, these were also used as duplicate for 
radiographic template. Multiple two-mm holes were placed into the dentures, at different levels and filled with gutta percha to create radio-opaque markers. A double scan technique was used, as described in previous studies. ${ }^{11}$ The CBCT data was formatted and transferred into a three-dimensional implant-planning software program (3Ddiagnostix.com). Using this software, implant positions and sizes, as they relate to both bone availability and associated vital structures, can be virtually evaluated and placed, prior to the implant procedure itself [Fig. $2 \& 3$ ]. After the plan was completed, the data were transferred to a milling centre; at which point a stereolithographic surgical guide (3DDX guide) was fabricated [Fig. 4].

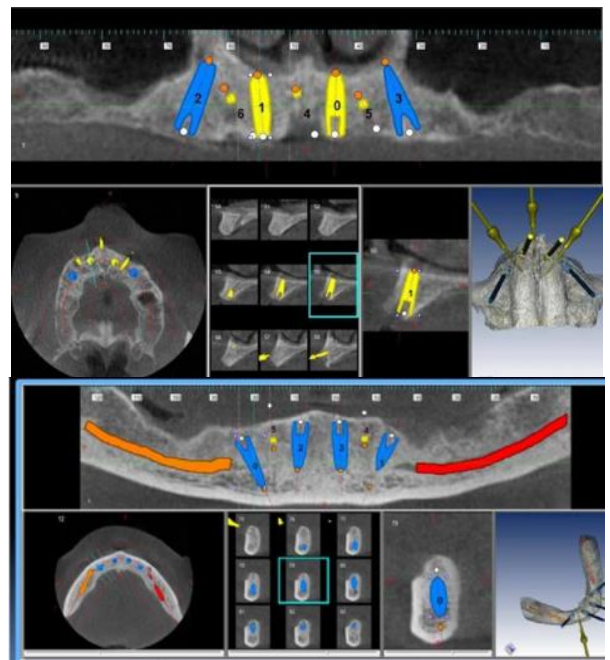

Fig. 2: Implant-planning maxillary and mandibular

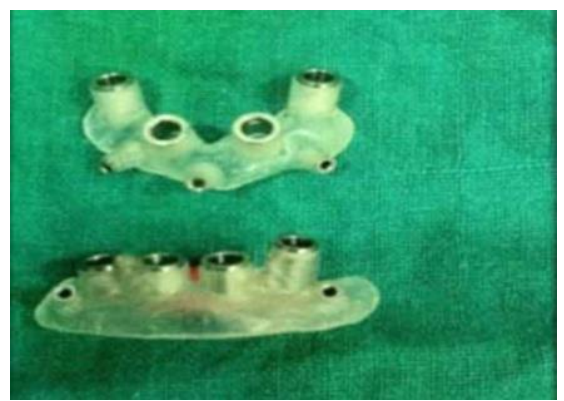

Fig. 3: Surgical guide

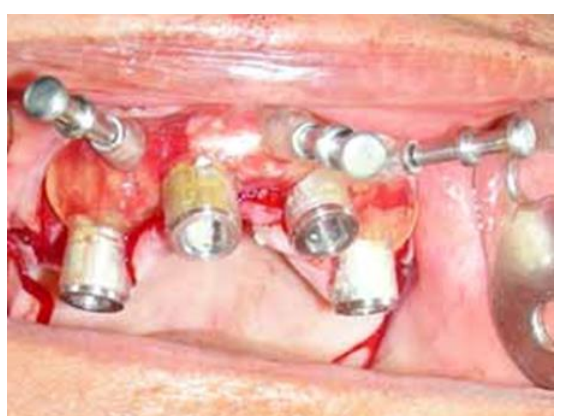

Fig. 4: Surgical guide in place-with retention
After achieving local anaesthesia, a mid-crestal incision at the anterior edentulous space was performed, and this was extended into the second premolar area using vertical releasing incisions. The surgical guide was then stabilized using guide pins, and the first osteotomy was prepared in the anterior positions. Maxillary osteotomy was completed before the initiation of mandibular osteotomy. Finally, TS implants (Osstem, South Korea) [Fig. 5] were placed. Finally, the flap was sutured using an interrupted 4.0 vicryl suture. A post-operative OPG was then taken to evaluate implant placement [Fig. 6].

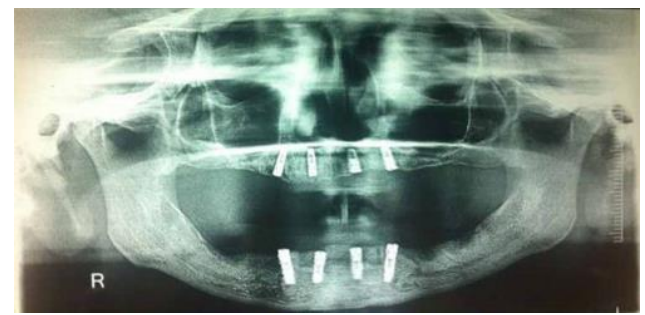

Fig. 5: Immediate post-operative OPG

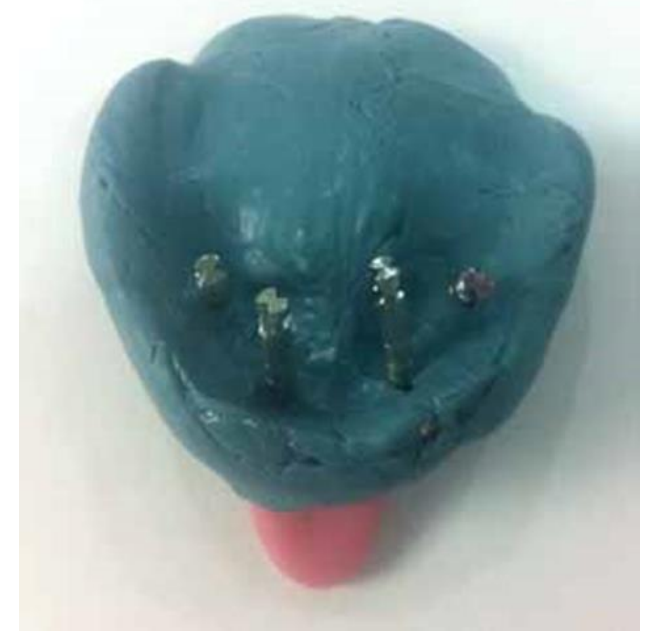

Fig. 6: Final impression-with precision coping screws

The sutures were removed after two weeks, and a denture was given to the patient after four weeks. At that time, the denture was relined using soft liner (Mucoprene $^{\mathrm{TM}}$ soft; Kettenbach).

The prosthetic phase was started five months after surgery. Second-stage surgery was performed and healing abutments were placed. The denture was again adjusted and relined. After a week, an alginate impression was taken to prepare a custom tray for a pick-up impression and impression was taken using open-tray impression copings and medium body impression material for both the arches, and sent to the lab [Fig. 7]. An implant-retained occlusal rim jig with bite registration was fabricated. With the help of NP cast abutments and pattern resin, a fit-verification jig was prepared; this was tried on the patients mouth to 
check the fit of the abutments, and for casting of the bar [Fig. 8]. Bite rim was obtained and bite registration done. The midline was marked and lip support checked. A wax try-in denture was prepared, tried and then sent to the lab for final processing of the hybrid prosthesis. Upon delivery of the final prosthesis, torqueing of the retention screws to $30 \mathrm{~N}$, and restoring the screw access holes was done. This was followed by radiographic confirmation of the fit of the prosthesis to the implant abutments, implant placement, and integration.

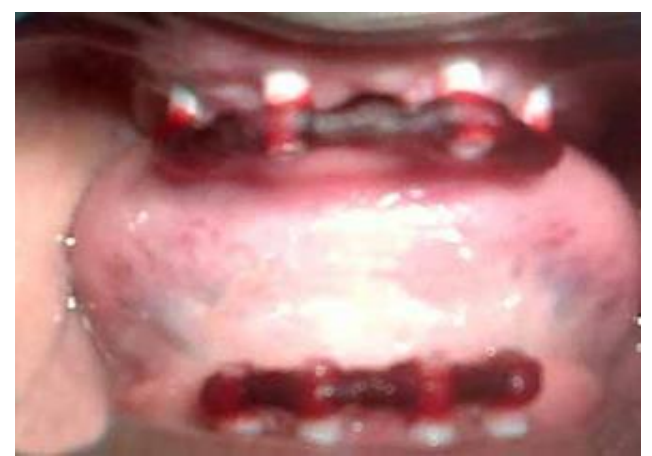

Fig. 7: Implant-retained occlusal rim

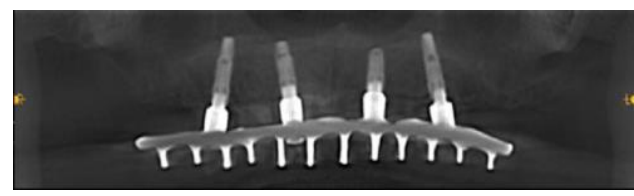

Fig. 8: Final prosthesis

\section{Methods}

Using the criteria suggested by Buser and Cochran et al., ${ }^{12}$ the implant survival rate was evaluated. Crestal bone changes induced by each implant were measured-taking the apex of the implant as the reference point and measuring until the crest of the bone at the mesial, distal, buccal, and lingual aspects at baseline, 9 and 18 months. The baseline for all measurements was functional loading. An independent researcher (C.R.) not involved in actual patient treatment, performed the radiographic analyses. Bone loss was calculated as the difference between the bone level at a certain point in time (six and 12 months) and that at baseline.

Implant success was defined according to criteria given by Adell et al., they determined that the mean bone loss for Branemark osseointegrated implants was $1.5 \mathrm{~mm}$ for the first year, followed $0.1 \mathrm{~mm} /$ year. ${ }^{13}$ The overall mean crestal bone level at the different intervals was compared using the repeated measure ANOVA test. Intervals were compared using the post-hoc Bonferroni test.

\section{Results}

The length of all eight implants was $11.5 \mathrm{~mm}$; the diameter of four out of the eight implants was $3.5 \mathrm{~mm}$, and that of the rest was $4.0 \mathrm{~mm}$. The two distal implants were tilted at between $35^{\circ}$ and $40^{\circ}$, depending on the anatomical conditions; the two mesial implants were oriented axially. The mean crestal bone loss values induced by all implants at 9 and 18 months were $0.75 \pm$ $0.23 \mathrm{~mm}$ and $0.89 \pm 0.31 \mathrm{~mm}$, respectively. This difference was not statistically significant $(p>0.05)$ at six months, but was at 12 months $(\mathrm{p}<0.05)$. Crestal bone loss induced by maxillary implants did not differ significantly from that induced by mandibular implants $(\mathrm{p}=0.487)$ after 18 months. Comparing the straight and tilted implants, a significant $(\mathrm{p}<0.05)$ difference was observed after 18 months, with slight bone loss among the tilted implants [Table 1, Fig. 9].

Table 1: Mean crestal bone level and bone loss at 6- and 12-month follow-up visits

\begin{tabular}{|c|c|c|c|c|c|c|c|}
\hline $\begin{array}{c}\text { Crestal } \\
\text { bone } \\
\text { level }\end{array}$ & $\begin{array}{c}\text { Baseline } \\
\text { mean } \pm \text { SD }\end{array}$ & $\begin{array}{l}9 \text { months } \\
\text { mean } \pm \text { SD }\end{array}$ & $\begin{array}{l}18 \text { months } \\
\text { mean } \pm S D\end{array}$ & p-value & $\begin{array}{c}\text { Difference } \\
\text { between } \\
\text { baseline } \\
\text { and } 9 \\
\text { months }\end{array}$ & $\begin{array}{c}\text { Difference } \\
\text { between } \\
\text { baseline } \\
\text { and } 18 \\
\text { months }\end{array}$ & $\begin{array}{c}\text { Difference } \\
\text { between } 9 \\
\text { and } 18 \\
\text { months }\end{array}$ \\
\hline Overall & $12.17 \pm 1.27$ & $11.58 \pm 1.41$ & $11.38 \pm 1.40$ & $0.049 *$ & $0.75 \pm 0.23$ & $0.89 \pm 0.31$ & $0.20 \pm 0.08$ \\
\hline Maxilla & $11.79 \pm 1.52$ & $11.09 \pm 1.67$ & $10.87 \pm 1.72$ & $0.068 *$ & $0.69 \pm 0.19$ & $0.91 \pm 0.37$ & $0.23 \pm 0.09$ \\
\hline Mandible & $12.55 \pm 1.04$ & $12.07 \pm 1.11$ & $11.89 \pm 0.96$ & $0.080^{*}$ & $0.48 \pm 0.17$ & $0.66 \pm 0.29$ & $0.18 \pm 0.11$ \\
\hline Tilted & $11.69 \pm 1.51$ & $10.85 \pm 1.59$ & $10.72 \pm 1.67$ & $0.041 *$ & $0.84 \pm 0.28$ & $0.98 \pm 0.38$ & $0.13 \pm 0.05$ \\
\hline Straight & $12.64 \pm 0.94$ & $12.31 \pm 0.84$ & $12.04 \pm 0.80$ & $0.081 *$ & $0.33 \pm 0.99$ & $0.61 \pm 0.21$ & $0.28 \pm 0.13$ \\
\hline
\end{tabular}

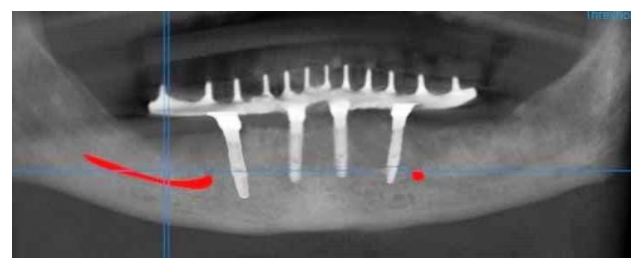

Fig. 9: Post-operative maxilla and Mandible after 18 months (Radiographic view)

\section{Discussion}

Technological advancements continue to revolutionize our ability to treat patients in a more efficient manner. Using CBCT imaging of available bone, anatomical issues that may be encountered during surgery can be revealed, and prosthetic tooth positioning can be planned. Computer-guided, template-based implant placement yields high implant survival rates - ranging from $91 \%$ to $100 \% .^{5}$ 
According to a recent review, the accuracy of guided implant surgery in vivo ranges from 0.95 to 4.5 $\mathrm{mm}$ at the apex of the implant. Consequently, a small deviation in the positioning of the implants can alter the thickness of the buccal or lingual cortical bone and result in additional bone loss. However, as the implants were placed without raising a flap in the same review, this was difficult to check. ${ }^{14}$ In our case, a flap was raised to remove this error.

In the present report, the mean marginal bone level after one year of functional loading $(0.89 \mathrm{~mm})$ was comparable with that found in previous studies involving the same type of implant. ${ }^{[6]}$ Tilted implants induced slightly more bone loss than straight, although the loss was still within the limits of the proposed criteria for implant success. ${ }^{13}$

Thus, All-on-4 combined with guided surgery can be called a successful amalgamation of the two techniques, with the possibility of improved outcomes for patients.

\section{Conclusion}

Considering the advantages and benefits of All-on4 combined with guided implant placement and restoration, we recommend this as a viable treatment alternative for rehabilitation of edentulous jaws.

Funding: No funding sources.

Conflict of interest: None declared.

\section{References}

1. Van Steenberghe D, Naert I, Andersson M, Brajnovic I, Van Cleynenbreugel J, Suetens P. A custom template and definitive prosthesis allowing immediate implant loading in the maxilla: a clinical report. Int J Oral Maxillofac Implants 2002;17(5):663-70.

2. Van Steenberghe D, Glauser R, Blombäck U, Andersson M, Schutyser F, Pettersson A, et al. A computed tomographic scan-derived customized surgical template and fixed prosthesis for flapless surgery and immediate loading of implants in fully edentulous maxillae: a prospective multi-centre study. Clin Implant Dent Relat Res 2005;7(1):11-20.

3. Sanna AM, Molly L, van Steenberghe D. Immediately loaded CAD-CAM manufactured fixed complete dentures using flapless implant placement procedures: a cohort study of consecutive patients. J Prosth Dent 2007;97(6):331-9.

4. Malo P, de Araújo Nobre M, Lopes A, Moss SM, Molina GJ. A longitudinal study of the survival of All-on-4 implants in the mandible with up to 10 years of followup. J Am Dent Assoc 2011;142(3):310-20.

5. Schneider D, Marquardt P, Zwahlen M, Jung RE. A systematic review on the accuracy and the clinical outcome of computer-guided template-based implant dentistry. Clin Oral Implants Res 2009;20(4):73-82.

6. Malo P, Rangert B, Nombre M. 'All on four' immediate function concept with Branemark system implants for completely edentulous maxilla: a 1 year retrospective clinical study. Clin Implant Dent Relat Res 2003;7(1):588-94.

7. Aparicio C, Perales P, Rangert B. Tilted implants as an alternative to maxillary sinus grafting: a clinical, radiographic and periotest study. Clin Implant Dent Relat Res 2001;3:39-49.

8. Krekamanov L, Kahan M, Rangert B, Lindstrom H. Tilting of posterior mandibular and maxillary implants of improved prosthesis support. Int J Oral Maxillofac Implants 2000;15:405-14.

9. Jensen OT, Adams WM, Cottam RJ, Parel MS, Phillips RW. The All-on-4 shelf: maxilla. J Oral Maxillofac Surg 2010;68:2520-7.

10. English CE. Critical A-P spread. Implant Soc 1990;1(1):2-3.

11. Ramasamy M, Giri RR, Subramonian K, Narendrakumar R. Implant surgical guides: from the past to the present. $J$ Pharm Bioallied Sci 2013;5(1):98-102.

12. Cochran DL, Buser D, ten Bruggenkate CM, Weingart D, Taylor TM, Bernard JP, et al. The use of reduced healing times on ITI implants with a sandblasted and acid-etched (SLA) surface: early results from clinical trials on ITI SLA implants. Clin Oral Implants Res 2002;13:144-53.

13. Adell R, Lekholm U, Rockler B, Brånemark PI. A 15year study of osseointegrated implants in the treatment of the edentulous jaw. Int J Oral Surg 1981;10:387-416.

14. D'Haese J, van de Velde T, Komiyama A, Hultin M, De Bruyn H. Accuracy and complications using computer designed stereolithographic surgical guides for oral rehabilitation by means of dental implants: a review of the literature. Clin Implant Dent Relat Res 2012;14:32135 .

How to cite the article: Bhasin M., Bhasin P., Gambhir N., Shewale A. All on 4 technique assisted with computer guided surgery - A case report with 18 months follow up. IP Int J Periodontol Implantol 2018;3(3):118-121. 